\title{
El programa mi casa, mi vida: análisis bajo la óptica de las reivindicaciones de los movimientos de vivienda
}

El Partido de los Trabajadores estableció en 2009 el programa Mi Casa Mi Vida (MCMV) visando ampliar el número de habitaciones formales. En la práctica, además de implementar una política pública habitacional, el programa también sirvió como instrumento de combate a crisis financiera global de 2008 , con el Estado asumiendo condiciones del empresariamiento financiero en su implementación. Delante de tal configuración, el artículo analiza si las reivindicaciones de los movimientos sociales de vivienda fueron atendidas por el Programa MCMV. Con miras a que investigaciones apuntan que el programa contribuyó con la asignación de los beneficiarios en las áreas periféricas y distantes de las ciudades, se percibe que, aunque haya aumentado el número de habitación formal, no fue capaz de ampliar el derecho a la ciudad para las capas populares. Por eso, son importantes movilizaciones sociales en pro de la búsqueda de derechos dentro del ambiente urbano, así como de cambios en el tratamiento de la cuestión de habitación establecida en el país.

Palabras-chave: Movimientos de vivienda; Programa MCMV; Sociedad Civil.

\section{My house, my life program: analysis from the perspective of the demands of the housing movements}

\begin{abstract}
In 2009, the Workers' Party established the My House My Life (MHML) program aimed at increasing the number of formal housing. In practice, in addition to implementing a public housing policy, the program also served as an instrument to combat the global financial crisis of 2008, with the State assuming the presuppositions of financial entrepreneurship in its implementation. Faced with such configuration, the paper analyzes if the claims of the social housing movements were met by the MHML Program. Considering that research shows that the program has contributed to the allocation of beneficiaries in the peripheral and remote areas of the cities, it is noticed that, although the number of formal housing increased, it was not able to extend the right to the city for the popular strata. Therefore, they are important social mobilizations for the search of rights within the urban environment as well as changes in the treatment of housing established in the country.
\end{abstract}

Keywords: Housing movements; MHML program, Civil Society.

Topic: Gestão Pública

Reviewed anonymously in the process of blind peer
Received: 11/01/2019

Approved: 21/04/2019
Marcus Vinicius Gonçalves da Silva (D)

Pontifícia Universidade Católica do Paraná, Brasil

http://lattes.cnpq.br/4352616650465977

http://orcid.org/0000-0003-2145-0871

marvin.gsilva@gmail.com

João André Nascimento Ribas (10)

Universidade Tecnológica Federal do Paraná, Brasil

http://lattes.cnpq.br/9189159171968264

http://orcid.org/0000-0002-7399-040X

joaribas@alunos.utfpr.edu.br
Referencing this:

SILVA, M. V. G.; RIBAS, J. A. N.. El programa mi casa, mi vida: análisis bajo la óptica de las reivindicaciones de los movimientos de vivienda. Revista Brasileira de Administração Científica, v.9, n.1, p.66-80, 2018. DOI: http://doi.org/10.6008/CBPC2179-684X.2018.001.0005 


\section{INTRODUCCIÓN}

La configuración de la relación entre Estado y sociedad civil brasileña pasó por modificaciones posteriormente la Constitución Federal de 1988, la cual reestableció el derecho político por diversas herramientas democráticas. Con la legitimación del pluralismo partidario y, a la vez, de la participación social advenidas de las experiencias de democracia participativa y directa y de manifestaciones sociales, que tuvieron papel fundamental en el desarrollo de la última Constituyente, la sociedad civil avanzó como agente de presión de los poderes de la Federación.

En ese contexto, las movilizaciones urbanas reciben destaque por, muchas veces, sean compuestas por movimientos sociales organizados, los cuales presentan reivindicaciones advenidas de la sociedad civil, como las relacionadas al derecho a la ciudad. Cabe en este momento destacar que se adopta la definición de Offe (1988) para delimitar el significado de movimiento social. El autor considera que movimientos sociales son grupos organizados que se destacan de la sociedad civil no organizada, con el fin de obtener una 'respuesta racional a un conjunto específico de problemas'.

De entre los movimientos organizados de la sociedad civil que se expresan en la coyuntura urbana, se tienen los movimientos de vivienda. Por intermedio de manifestaciones u ocupaciones en inmóviles o terrenos despejados que no cumplen sus funciones sociales, ellos buscan presionar el gobierno por formulación e implementación de políticas públicas más eficaces vueltas a la habitación y al derecho a la ciudad para las capas populares.

Sus luchas son motivadas delante del fenómeno de la urbanización, que se potencializó globalmente durante la industrialización del siglo XX, y aún presenta fuerzas de crecimiento en el escenario posindustrial, cargando consigo diversos problemas sociales, como la pobreza, habitaciones informales y la exclusión de una cuota de la sociedad civil del derecho de vivienda. El mayor desafío entonces es de enfrentarse la realidad impuesta por la globalización, donde las ciudades son configuradas de forma a atender a los intereses de los detentores de poder hegemónico global.

En 2009, fue instituido el programa Mi Casa Mi Vida (MCMV) como forma de atención a las demandas sociales de habitación formal para las capas populares. Tenido por su gobierno idealizador como un avance en los derechos sociales y una reconciliación entre el capital y el trabajo, el programa se encuentra en su tercera fase, que seguirá hasta $2018^{1}$. Sin embargo, delante de la contextualización empresarial en que fue desarrollado, como respuesta la crisis financiera global de 2008, el artículo pretende analizar si las reivindicaciones de los movimientos de vivienda fueron atendidas por el MCMV, asumiendo como recorte temporal el periodo de 2010 a 2014, que envolvió sus fases uno y dos. Para eso, se realizará una investigación bibliográfica de carácter descriptivo con base en los resultados cuantitativos y cualitativos del programa.

El capítulo siguiente a esta introducción presentará las características de la política habitacional de Brasil, iniciando con las acciones del Banco Nacional de Habitación (BNH) durante el Régimen Militar y,

\footnotetext{
${ }^{1}$ La Crisis Financiera Global de 2008, también conocida como gran Recesión advino de problemas financieros de Los Estados Unidos en el sector inmobiliario, "causada por la la desregulación de mercados financieros y por la especulación salvaje que esta desregulación permitió" (BRESSERPEREIRA, 2010). Representa la mayor crisis financiera vivida desde 1929.
} 
posteriormente, contextualizando el escenario en que se desarrolló el Programa MCMV por el Partido de los Trabajadores (PT). También serán abordados los movimientos por vivienda delante de la coyuntura de las políticas públicas habitacionales durante estos procesos. Posteriormente, el capítulo intitulado de "El Programa MCMV: inclusión excluyente" realizará una crítica de los resultados del programa, con base en las reivindicaciones de los movimientos por vivienda, para apuntar en las conclusiones perspectivas con relación al derecho a la vivienda y a la ciudad en Brasil.

\section{REVISIÓN TEÓRICA}

\section{La Coyuntura de la Política Habitacional de Brasil}

El urbanismo es definido como una actividad formada por determinado territorio con trazos de piedra, de cimento o de metal (LEFEBVRE et al., 2004). Pero, para comprender el fenómeno de la urbanización, es necesario ir además de su modelado físico, a fin de disecar su relación entre el capital y el modelado social de la urbanización, principalmente con relación a las trasformaciones provenientes de la profundización del proceso de globalización neoliberal. Por eso, Lefebvre (1991) introduce el concepto de derecho a la ciudad como un derecho de no exclusión de la sociedad de las calidades y de los beneficios de la vida urbana, incluyendo el comercio, el ocio y la habitación.

Muy, aunque la discusión sobre políticas habitacionales envuelva un periodo que se inicia en 1890, conforme apunta Bonduki (2014), fue sólo durante el Régimen Militar² que efectivamente se implementó el primero programa habitacional en Brasil. El período del Régimen Militar presenta una creciente urbanización dispersa, formando metrópolis caracterizadas por el surgimiento de barrios marginales y ocupación desordenada, donde las financiaciones habitacionales concedidas por el BNH beneficiaron más la clase media que las clases más pobres.

La política de habitación de 1966, advenida del Régimen Militar, tenía como base un modelo de financiación habitacional con captura del Fondo de Garantía de Tiempo de Servicio (FGTS) y del Sistema Brasileño de Ahorro y Préstamo (SBPE), administrado por el BNH (CARDOSO et al., 2013). Pero, así como la política económica del Régimen Militar, el BNH entró en crisis durante los años de 1980. Mientras el país pasaba por una agitación social delante de las movilizaciones en pro de la democracia, que culminaron en la redemocratización de Brasil, el BNH perdió fuerzas delante de la crisis, alcanzando la clase trabajadora y, consecuentemente, el FGTS, causando impacto en la política habitacional.

En 1986, se inicia un periodo de ausencia efectiva de una política nacional de habitación, extendiéndose hasta 2003, cuando hubo la creación del Ministerio de las Ciudades. Aunque la defensa del presidente Tancredo Neves, elegido indirectamente en 1985, a favor de la necesidad de políticas habitacionales, José Sarney, al asumir la presidencia del país en el mismo año, en virtud del fallecimiento de Tancredo Neves, promueve la desarticulación del BNH. Con la extinción del BNH, los programas federales

\footnotetext{
2 Instituido en 1964, posteriormente a un golpe civil-militar para derrumbada del entonces presidente João Goulart, cuyos objetivos envolvían el establecimiento de políticas de reforma de base heterodoxas, siguiendo hasta la década de 1980, cuando hubo la redemocratización del país y promulgación de la Constitución Federativa de 1988.
} 
comenzaron a privilegiar los municipios como los agentes habitacionales y, como consecuencia, la política habitacional queda subordinada a órganos dispersos hasta la creación del Ministerio de las Ciudades.

En los años de 1990 son experimentados algunos programas con enfoque en la cuestión habitacional. Durante el gobierno de Fernando Henrique Cardoso son creados el sistema de autofinanciamiento y el Programa de Arrendamiento Residencial (PAR), contribuyendo para la especialización de empresas orientadas a los productos para sectores de renta media y baja. Entre los años de 1993 y 2002, hubo la consolidación de la estabilidad política y económica, concomitante a las políticas neoliberales, con la apertura comercial, desreglamentaciones y privatizaciones. La Unión descentraliza responsabilidades para los Estados y municipios, que resultaron en guerras fiscales y la concurrencia entre ciudades (KLINK, 2013) y problemas en el gerenciamiento de las políticas urbanas.

Ya en 2000, el Congreso aprueba el proyecto de habitación como un derecho social. El Proyecto Vivienda surge entonces como una propuesta de sopesar el déficit habitacional del país, reglamentando la política urbana de la Constitución. La propuesta vincula sus instrumentos al Plan director Municipal, y de esa manera transfiere responsabilidad a los municipios $y$, al mismo tiempo, a las presiones de los movimientos populares (BONDUKI, 2014). En 2001, es instituido el Estatuto de las Ciudades, que representa un avance de las luchas por la reforma urbana ${ }^{3}$, pues describe instrumentos capaces de materializar el derecho a la ciudad (BASSUL, 2002).

El Proyecto Vivienda culminó con la creación del Ministerio de las Ciudades y la Política Nacional de Habitación, en 2004, en el gobierno de Luiz Inácio Lula da Silva, del PT, trayendo para el nivel nacional la responsabilidad por las políticas urbanas. La creación del Ministerio de las Ciudades en el inicio del gobierno de Lula advino de las propuestas del Proyecto Vivienda, que proponía la creación del Sistema Nacional de Habitación, la gestión democrática de la Política Nacional y Urbana y la institución del Fondo Nacional de Habitación, para direccionar el FGTS para las capas de baja renta (CARDOSO et al., 2013).

En el gobierno del PT, hubo la maduración de las políticas urbanas, como la composición del Consejo de las Ciudades, en 2004; y el Fondo Nacional de Habitación de Interés Social (FNHIS), en 2005, de carácter práctico y más municipalizado, objetivando subsidios directos a la habitación de empleados de baja renta (CARDOSO et al., 2013). En el año de 2006, ocurre el lanzamiento del Programa de Aceleración del Crecimiento (PAC), visando el desarrollo de la infraestructura nacional y urbanización de asentamientos; y en 2007, el Programa Crédito Solidario, vuelto para las necesidades habitacionales de la populación de baja renta, bajo provisión habitacional basada en la autogestión (BONDUKI, 2014).

La formulación del Plan Nacional de Habitación (PlanHab) ocurre posteriormente a la creación de un fondo en el área de habitación en 2008, con los objetivos de: financiación y subsidio; arreglos institucionales; cadena productiva de la construcción civil; y política urbana, agraria y ambiental. Tal documento, de entre otros temas, discute el problema de la exclusión de la población de baja renta de los centros urbanos debido

\footnotetext{
${ }^{3}$ La reforma urbana envuelve los temas de conquista del derecho a la ciudad, la gestión democrática de la ciudad y la función social de las propiedades. "En Brasil, la lucha por la llamada "reforma urbana" nació del abismo que divide los espacios (ia veces contiguos!) reservados a los ricos y a los pobres en nuestras ciudades" (BASSUL, 2002).
} 
al aumento de precio de la tierra, ocasionando los vacíos en la ciudad. También preveía la urbanización de asentamientos precarios donde vivían 3,3 millones de familias (BONDUKI, 2014)

En 2009, fue instituido el MCMV ramificación del PAC, desarrollado por el Ministerio de la Hacienda en conjunto con la Casa Civil, está dirigida por Dilma Rousseff. Para el gobierno, el paquete habitacional de construcción de viviendas lanzado en abril de aquel año por el gobierno Lula se trataba de una reacción visando a la inclusión de sectores que hasta entonces no poseían acceso a la vivienda. Pero, como será presentado en el próximo capítulo, el paquete sirvió también como respuesta a la crisis financiera global de 2008, para estimular la economía y la generación de empleos.

Inspirado en el protagonismo del sector empresarial chileno y mexicano para la producción habitacional, el programa buscó contribuir con crédito tanto para el consumidor cuanto para el productor. Con la crisis financiera global de 2008, el gobierno necesitó adoptar políticas anticíclicas en la tentativa de compensar la retracción del sector privado. El equipo ministerial del presidente Lula al garantizar líneas de crédito a los consumidores e incentivos a las industrias automovilísticas, obtuvo resultados económicos estables además de mantener las inversiones del PAC y movilizar la Petrobras para incrementar las inversiones. De ese modo, con vistas a combatir la crisis, también alegó utilizar el MCMV también como la una política anticíclica, con foco en la atención de familias con renta de hasta 10 sueldos mínimos (CARDOSO et al., 2013). El programa fue continuado por su sucesora en la presidencia, Dilma Rousseff, también del PT.

En las palabras de Klink (2013) el régimen keynesiaño "ha evolucionado para un régimen estatalespacial competitivo y reescalonado", Así, en una guerra de suma cero, hasta aún aquellos gobiernos considerados más heterodoxos tuvieron que actuar en el mantenimiento del sistema de empresariamento, como en el caso del PT, de origen ideológico de izquierda, ya que los intereses de las capas populares también estaban atrapados al capital financiero que envolvía la competición y la búsqueda de más recursos para la ciudad. En ese ínterin, el gobierno buscó asegurar las ventajas competitivas nacionales al establecer una alianza con la clase empresarial.

Así, mantuvieron las prácticas liberales reestablecidas en los años de 1990. La urbanización, que debería actuar como el proceso social decurrente del espacio, por medio de la interconexión de actores objetivos y agendas diversas, asumió prácticas de carácter clasista estrictamente definido. Ella pasó a definir diferentes arreglos institucionales, como sistemas políticos y administrativos y jerarquías de poder, que funcionan en consonancia con el dinamismo y la transformación del capitalismo. La visión civilista de propiedad particular, sobre la égida liberal, concentra la ideología de propiedad como mercancía en América Latina, agravada por las determinaciones burocráticas contractuales, comerciales y de planificación tecnocrático elitista, en detrimento de los intereses de capas populares (FERNANDES, 2006).

Delante de las políticas habitacionales presentadas, es importante considerar como ocurrió la actuación de los movimientos sociales urbanos, teniendo en vista que estos son capaces de movilizar intereses de parcelas de la sociedad civil de forma organizada y demonstrar sus insatisfacciones a respecto de la configuración urbana. 
Bajo este aspecto, la coyuntura política se modificó con la institución de la Constitución Federal de 1988, la cual representa un marco divisorio sobre el establecimiento de la legalidad de acciones de las manifestacioes sociales. Pero sus luchas ya se hacían presentes mucho antes de tal Constitución, como forma de protestas especialmente direccionadas para el fin de Régimen Militar establecido en el país; luchas que posibilitaron la inclusión de la participación social en la vida política en el texto constitucional.

\section{Los movimientos de vivienda}

A finales de la primera mitad del siglo XX, aliadas a un período de fuerte industrialización conocido como nacional-desarrollo, y de intenso proceso de urbanización excluyente, el cual promovía una segregación socioespacial que llevó la población carente para las áreas periféricas, los movimientos sociales se fortalecieron en las zonas urbanas. Tal fato es comprensible delante de la aceleración del urbanismo como forma de establecimiento de relaciones sociales.

Sin embargo, el programa habitacional desarrollado durante el Régimen Militar, bajo el mando del $\mathrm{BNH}$, fue desarrollado en una coyuntura adversa a la participación social, en el momento en que los derechos civiles y políticos de los ciudadanos estaban restringidos. En la segunda mitad del siglo XX, más precisamente a fines de la década de 1970, ocurrió un gran proceso de articulación y organización de los movimientos sociales frente a los indicios de crisis de la gobernabilidad del Régimen Militar.

Esos movimientos sociales, movilizados juntamente con el Movimiento Democrático Brasileño (MDB) pasan a crear mecanismos para rearticular la sociedad civil, buscando establecer nuevos proyectos para provocar un cambio social en el país. Los impulsos y la pluralidad alcanzada por los movimientos sociales en este período son descriptos por Soares do bem (2006):

El cuestionamiento del modo universalista de organización de la clase trabajadora llevó a la realización del I Congreso de la Mujer Metalúrgica, el año de 1978, en São Bernardo do Campo, abriendo el camino para un repaso de las estrategias de lucha de la clase trabajadora en varios campos y forzando la incorporación de particularidades de género, "raza", cultura y etc. en la formulación del ideario de las luchas. Se iniciaron las grandes huelgas de grandes categorías socioeconómicas, impulsadas por el movimiento de los metalúrgicos en el Grande ABC, en São Paulo. En 1979 fue creado, en Santa Catarina, el Movimiento de los Sintierra, prenunciando la creación del Partido de los Trabajadores, que ocurrió en 1980. Es del mismo periodo el movimiento de organización de las chabolas, principalmente en São Paulo, en Rio de Janeiro y en Belo Horizonte.

En la década de 1980, frente al agotamiento del modelo nacional- desarrollista, los movimientos sociales ganaron alta visibilidad, fortaleciendo la sociedad civil por medio del movimiento 'Directas Ya', que promovió un levante victorioso contra el ya estremecido Régimen Militar. La Asamblea Nacional Constituyente representó una conquista del espacio de la lucha política por la sociedad civil, una vez que fue alcanzada por medio de una grande articulación de las demandas populares, enfrentando las fuerzas conservadoras que eran contra su participación.

La Constitución de 1988 abrió espacio para la democracia participativa y directa, bien como, para expresiones de la sociedad civil presentadas por los movimientos sociales, que diferentemente de momentos anteriores de la historia del país, pasaron a ser provenidos de libertades legales para iniciativas de 
manifestaciones. Así, el escenario político brasileño pasó a configurarse por la participación de sujetos sociales de forma representativa, elegidos por el sufragio universal, afiliados a un subtítulo partidario y la participación de la propia sociedad civil que pasó a luchar por el poder dentro de la arena política, manifestándose de varias formas, sea por movilizaciones sociales o por la toma de espacios institucionales.

En 1987, surge el Fórum Nacional por la Reforma Urbana, que influenció la introducción de los principios de la función social de la propiedad en la Constitución Federativa de 1988. De ese modo, la Constitución tornó la habitación responsabilidad de las tres esferas del gobierno, ampliando las reivindicaciones locales de movimientos sociales sobre derecho a la vivienda. En ese enfoque, los movimientos sociales urbanos reencendieron el debate sobre el derecho a la ciudad, con destaque a los movimientos de vivienda que buscaban conquistar habitaciones formales para una población que no poseía el acceso, aun siendo tal derecho constitucionalmente garantizado en el artículo 6.

La década de 1980 es marcada por la constitución de dos principales movimientos de vivienda de Brasil: la Unión Nacional por Vivienda Popular y el Movimiento Nacional de Lucha por Vivienda. Además de estos, surgen también la Confederación Nacional de las Asociaciones de Moradores en 1982, y la Central de los Movimientos Populares, en 1993, que buscaban abrazar diversos movimientos sociales, incluso aquellos de vivienda (FERREIRA, 2012). Otro movimiento social urbano que merece destaque en los últimos años, dadas sus movilizaciones, con foco en eventos nacionales como la Copa del Mundo, en 2014, es el Movimiento de los Trabajadores Sin-Techo (MTST).

El Consejo de las Ciudades se tornó el principal canal de comunicación de los movimientos de vivienda con el Gobierno Federal, pero sus voces no se limitan solamente a este instrumento. Estos movimientos realizan diversas acciones para expresar sus demandas, sea por fórums nacionales e internacionales, caravanas y marchas; sea por bloqueo de carreteras, pues, de esta manera, el movimiento consigue paralizar la circulación de mercancías, promoviendo un efecto parecido con lo que ocurriría con un paro del sector, ocasionando pierdas financieras al capitalista; o por la ocupación de áreas o edificaciones urbanas desocupadas que no cumplen con sus funciones sociales.

Ya en 2013, Brasil se tornó escenario de diversas manifestaciones urbanas, donde diferentes grupos organizados o no de la Sociedad Civil fueron a las calles reivindicar políticas públicas efectivas en las más diversas áreas sociales. De entre estas manifestaciones, se destacan las jornadas de junio/julio de $2013^{4}$, iniciadas por el Movimiento Pase Libre (MPL), pero que también contaron con la participación de movimientos de vivienda, como el MTST.

Conforme apunta el MTST, a partir del momento en que el acceso a la vivienda se tornó un privilegio, ocupar se volvió un derecho, con el fin de que no faltan habitaciones en el Brasil con relación a la cantidad de sin-techos (BOULOS, 2014). La intención de las ocupaciones es de presionar los propietarios privados y el

\footnotetext{
${ }^{4}$ A pesar de las jornadas de junio/julio de 2013 hayan movilizado un gran número de otros movimientos o individuos de la sociedad, la mayor conquista advino de la reivindicación del MPL, que inició las jornadas, el cual consiguió que sus propuestas (que era en contra el aumento de R\$ 0,20 en la tarifa del transporte público en la ciudad de São Paulo) fueron acatada por el Poder Público.
} 
Estado a respecto del problema social de la vivienda. La ocupación estaría entonces no basada en la propia Constitución, que estipula la función social de las propiedades en sus artículos 5ำ y 170.

Visto así, ocupar sería un proceso de reafirmación de un derecho previsto en la Constitución, que garantiza a todos los ciudadanos, como el derecho fundamental, el acceso a la vivienda. De esa manera, el proceso de ocupación demuestra la inercia del Estado en formular políticas públicas efectivas que visen garantizar el acceso de la población de baja renta a la vivienda.

[...] la ocupación, para fines de vivienda, de una tierra improductiva, abandonada, sobre la cual el propietario no ejerce el derecho de posesión, que no sirve siquiera al ocio y que por su localidad y tamaño precisa, necesariamente, atender a una finalidad social, no es mera invasión. Se trata, en verdad, de una acción política que visa poner a la prueba la eficacia de los preceptos constitucionales, cabiendo esclarecer que esa no es una temática exclusiva del medio rural ya que las normas jurídicas mencionadas no hacen esa diferenciación y también la Constitución de 1988 pasó a admitir la usucapión de inmuebles urbanos (artículo 183).

Para Harvey (2014) "La idea de derecho a la ciudad no surge fundamentalmente de diferentes caprichos y modismos intelectuales [...] Surge básicamente de las calles, de los barrios, como un grito de socorro y amparo de personas oprimidas en tiempos de desespero". Demuestran así, descontentos de la sociedad con relación a las políticas establecidas por el Estado. Los movimientos de vivienda constantemente destacan la urgencia de una reforma urbana, tema inerte desde la década de 1960, que incluya la democratización del acceso a la ciudad. Sin embargo, aun considerando los avances de las políticas urbanas en el país, las leyes establecidas y la participación social aún están distantes de los anhelos de los movimientos de vivienda y de una reforma urbana (FERREIRA, 2012).

Se cree que las políticas neoliberales de los años de 1990 colaboraron para un proceso de urbanización excluyente y contribuyeron para la segregación urbana de gran parte de la población. Así, la reforma urbana objetivaría la modificación estructural de la ciudad, actuando en la contención de la especulación inmobiliaria y minimizando el crecimiento desordenado de las ciudades.

El crecimiento urbano desordenado y continuado, resultante del período del Régimen Militar con la institución de políticas neoliberales, incluye las habitaciones formales establecidas sin el debido planeamiento de espacio, excluyendo parte de la población del derecho a la ciudad. Con base en las reivindicaciones presentadas por los movimientos de vivienda y por parcelas de la sociedad civil a respecto del tema, el gobierno del PT absorbió en su agenda el atendimiento a la cuestión del déficit habitacional, en 2009, con el establecimiento del MCMV. Sin embargo, en la dicotomía del programa MCMV, en atender a las demandas de la sociedad civil y, a la vez, en beneficiar el sector empresarial, se instituyó el cuestionamiento sobre los resultados del programa delante de las demandas de los movimientos de vivienda.

\section{Resultados del Programa MCMV}

El programa MCMV, inicialmente, señaló atendimiento a las demandas de los movimientos de vivienda, como el derecho a la habitación formal, pero, sin enfatizar cuestiones con relación al derecho a la ciudad. Dada la ideología de la casa propia difundida en el Brasil, el establecimiento de incentivos a la 
adquisición de viviendas por el gobierno por medio del MCMV, surge como una especie de apaciguamiento de las luchas sociales en relación con el sistema capitalista excluyente.

La movilización del imaginario popular cuanto a la seguridad que la casa propia proporciona, contribuyó para la propaganda política realizada encima del programa y para su consolidación. Instituido en 2009, el MCMV pasó a entregar unidades listas sólo en 2010, año en que efectivamente se puede medir el impacto del programa en la cuestión de déficit habitacional. La fase uno del programa siguió hasta 2011, mientras que la fase dos acabó en 2014.

Con base en los datos cuantitativos, es posible afirmar que el programa colaboró con la reducción de déficit habitacional del país, unas de las principales reivindicaciones de los movimientos de vivienda. Entre 2009 y 2014, fueron realizados 4,2 millones de contratos y, a partir de 2010, entregues 2,5 millones de casas y apartamentos, sumando un total de inversión de R\$ 270 mil millones. El periodo comprendido entre 2010 y 2014 presentó resultados positivos sobre aumento de habitaciones formales. Con base en la metodología de la Fundación João Pinheiro, el déficit habitacional en 2014 fue de 6.198,3 millones de familias, contra 6.940,7 millones en 2010. En el periodo, la caída del déficit habitacional fue del 2,8\% al año, como muestra la figura 1:

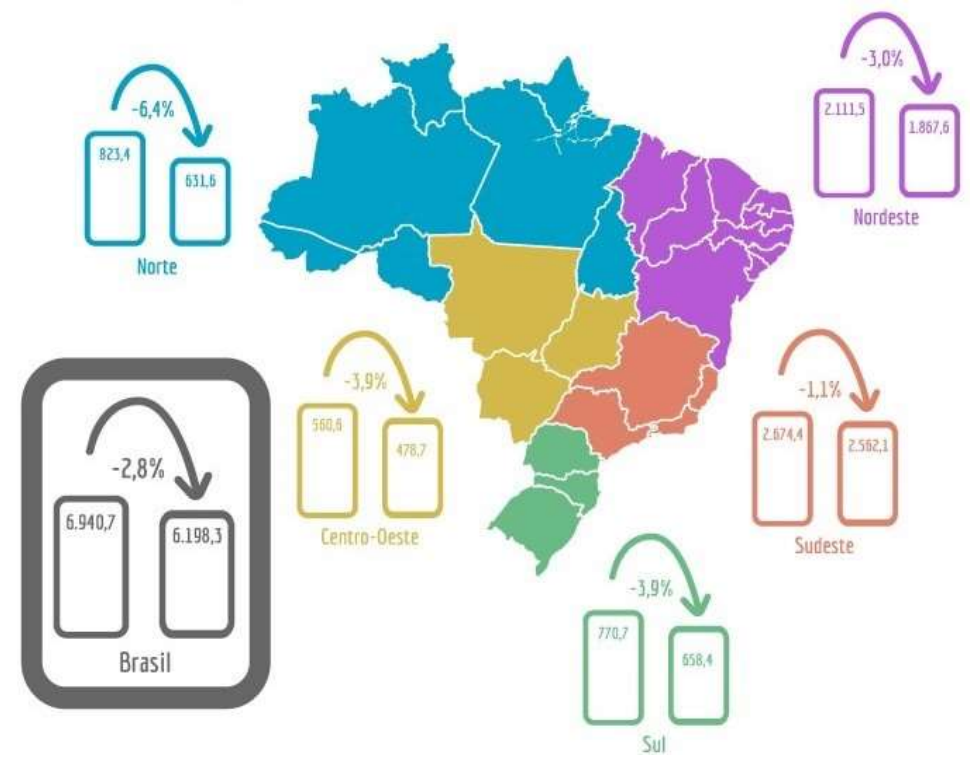

Figura 1: Reducción de déficit habitacional entre 2010 y 2014 (miles de familias).

Sin embargo, la metodología de implementación realizada contrarió diversas defensas de tales movimientos, como la propia participación social. Con medidas vueltas al empresariamento urbano, en la elaboración del MCMV, El Ministerio de las Ciudades no fue incluso en las negociaciones, y el Consejo de las Ciudades siquiera fue oído, además de no haber sido providenciadas las medidas estipuladas en el Estatuto de la Ciudad. Todo fuera elaborado en consenso entre la Casa Civil, el Ministerio de la Hacienda y los representantes inmobiliarios y de la construcción, enfocando más en el combate a la crisis financiera global de 2008 por el estímulo al sector de construcción civil, sin combatir la especulación agraria.

En cuanto a la intención de inducir una política anticíclica frente a la crisis financiera global de 2008, el paquete poco contribuyó con otros sectores económicos, en la industria, visto que el público difícilmente 
tendría recursos para ejecutar los acabados y adquirir los mobiliarios, mientras que la gran cantidad de empleos generados en la construcción civil se presentó como de calidad dudosa. Para Fix et al. (2009), debido al programa no haber criado nuevos negocios y no haber impactado en el superávit primario, no puede ser considerado como una política anticíclica como el gobierno defendía.

En el tocante a la divergencia del programa MCMV con la política urbana, Bonduki (2009, citado por CARDOSO et al., 2013) apunta los conflictos administrativos entre las esferas municipal, provincial y federal, debido a las diferentes competencias advenidas del programa, de la Constitución de 1988 y de la política habitacional. Los municipios sufrieron diversas presiones del paquete, que contrariaron las legislaciones locales al exigir cambios de perímetros urbanos, y tomando direcciones opuestas al preconizado en el Estatuto de la Ciudad.

Los municipios pasaron a asumir el arcabuco socioeconómico que envolvía las nuevas viviendas, como infraestructuras, transporte y servicios públicos, ya que el programa no está direccionado para la verticalización de la ciudad debido al menor coste de terrenos en áreas periféricas. Se verificó la falta de una mayor bisagra del programa con política urbana en el país, aliado la institución de políticas de transferencias de recursos para los municipios, con vistas a la atención de terrenos en áreas periféricas. Se verifico la falta de una mayor articulación del programa con política urbana en el país, aliado a la institución de políticas de transferencias de recursos para los municipios, con vistas al atendimiento de las demandas resultantes de las nuevas viviendas.

El programa MCMV llevó al crecimiento horizontal urbano, distanciando las capas más pobres del área central de los municipios, desconsiderando deliberadamente la función social de las propiedades urbanas establecidas. La cuestión de la hegemonía del sector privado como el agente fiscal acarreó la construcción de viviendas en terrenos de bajo coste, o sea, aquellos con problemas de accesibilidad y de infraestructura, originando en nuevos gastos en el presupuesto del ente público. La ausencia de reglamentación del mercado inmobiliario por el Estado acarreó una exclusión socioespacial de la capa más pobre para áreas de riesgo o de protección ambiental, como de manantiales, que, juntamente con la polución causada por las grandes industrias, provocan amenazas al abastecimiento de agua.

La localización de las viviendas, más enfocada en las regiones periféricas, impactó las cuestiones agrarias y la elevación del precio de las propiedades. Con eso, el programa colaboró con el mantenimiento del carácter de ciudades-dormitorio alrededor de un municipio desarrollado o una ciudad-sede que atrae mayores inversiones, al tiempo que la realización de inversiones en infraestructura, salud, transporte, etc. en las regiones más pobres se hace precarios. Contribuyó juntamente para el vaciamiento de la preocupación de ocupación de áreas céntricas y evidenció incongruencia como el modelo de ciudad compacta (FIX et al., 2013).

De ese modo, la segregación espacial se mantuvo con vistas a los intereses de la lógica productivista, pues las casas fueron construidas en áreas de periferias urbanas o en áreas rurales que se transformaron en urbanas. El paquete del programa no estimuló la ocupación de los inmuebles libres, favoreciendo la especulación inmobiliaria y el descumplimiento de la función social de la propiedad (FIX et al., 2009). 
Frente a la segregación socioespacial, los movimientos de vivienda continuaron actuando como los agentes de presión bajo el statu quo del uso de propiedades urbanas, realizando ocupaciones de inmuebles que no cumplen sus funciones sociales. Otras críticas apuntan el privilegio dado al sector privado y la baja calidad de los emprendimientos y la desigualdad de distribución de los recursos (CARDOSO et al., 2013).

La política de movilidad en Brasil, por ejemplo, es bastante contradictoria, pues al mismo tiempo en que estudios apuntan las deficiencias del sistema modal y la falta de inversiones en transportes colectivos, incentiva el uso de vehículos particulares con políticas de reducción de impuesto sobre productos industrializados (IPI) para compra de vehículos, entre 2012 y 2014 . Trae así, un escenario de caos urbano, precarizando la calidad de vida y el desarrollo económico y social, visto que la ineficiencia de la movilidad urbana perjudica física y psicológicamente la población.

Delante de eso, el programa MCMV dio secuencia la mercantilización de la habitación, visto que las contratistas recibieron cerca de 1,4 mil reales por $\mathrm{m}^{2}$, mientras que campañas autogestionadas de los movimientos populares podrían construir el metraje dos a tres veces más barato (FIX et al., 2009). Aún, no hubo la preocupación con la calidad del producto y su impacto ambiental, al construir viviendas de cerca de $7 \mathrm{~m}^{2}$ por habitante para una familia de cuatro personas. El arquetipo de la mayoría de las viviendas se asemeja a los de los presidios cuanto a sus fachadas, ventanas y muros.

Al sufrir presiones de los movimientos sociales de vivienda, el gobierno instituyó en el año de 2009, una modalidad específica para el programa, vuelta para la producción social de viviendas realizadas por los futuros beneficiarios: el Mi Casa, Mi Vida (Entidades) ${ }^{5}$, objetivando acciones cooperativistas para ampliación de viviendas para las familias de baja renta. Sin embargo, las reglas establecidas, semejantes aquellas vueltas a las empresas privadas, dificultaron el proceso de producción por las asociaciones y cooperativas habitacionales, como apunta Ferreira (2012):

La lógica de mercado presente en el PMCMV - Entidades hace la concretización de los proyectos por los grupos de hecho populares una odisea sin fin, absorbiendo buena parte de las energías de sus miembros y comprometiendo los objetivos emancipatorios que animaron la lucha por el acceso a un fondo popular para la vivienda (FERREIRA, 2012).

Como consecuencia, conforme estudios de Fix et al. (2009), el modelo de previsión habitacional ofrecido fue realizado casi que exclusivamente por producción directa de las constructoras privadas ( $97 \%)$, y solamente el 3\% por entidades sin fines lucrativos. Bajo tal medida, el gobierno reconoció su favoritismo a la iniciativa privada. La producción fue hecha por oferta, o sea, la constructora era responsable por el terreno, proyecto y construcción y, posteriormente vendía a la Caja Económica Federal, sin riesgo de incumplimiento de compradores o vacancia. El formato visaba el desarrollo económico por medio de emprendimientos, pero tuvo en su ejecución la concepción especulativa, sujeta a los peligros inherentes del mercado inmobiliario, haciendo que el sector público asumirá los riesgos de la iniciativa privada.

La lógica capitalista del programa MCMV se expresó de varias formas, de entre ellas la economía realizada por las constructoras con la adopción de materiales de menor coste, sin embargo, sin que ese coste

\footnotetext{
${ }^{5}$ Tal programa es "direccionado a las familias de renta familiar mensual bruta de hasta $\mathrm{R} \$ 1.600,00$ y estimula el cooperativismo y la participación de la población como protagonista en la solución de sus problemas habitacionales" (CAIXA ECONÓMICA FEDERAL, 2017).
} 
fuera repasado a los prestatarios del programa, teniendo en vista los techos de financiamiento, culminando en mayor logro para las empresas. Esta medida también tuvo impacto en la calidad de los productos y servicios, pues el sector privado búsqueda ampliar la escala de emprendimientos y estandarizar las viviendas, estandarizando materiales y procesos productivos (CARDOSO et al., 2013).

Los recursos del programa son desigualmente distribuidos por estar atados a la iniciativa privada local que atienda a los requisitos básicos del programa. Por eso, diversos municipios con déficits habitacionales no son plenamente atendidos, teniendo en vista la ausencia de tal iniciativa privada, la cual también se sobresale delante de los movimientos sociales, que perdieron su participación garantizada en la política habitacional (CARDOSO et al., 2013). Incluso llevando en consideración el objetivo del gobierno de atender a su electorado - la parcela más pobre de la población -, el programa pasó a atender en mayor número a la populación de tres a diez sueldos mínimos, teniendo en vista los intereses del mercado.

Tales hechos exponen la contrariedad del programa con las reivindicaciones de los movimientos de vivienda, pues estos buscan no sólo el acceso a la habitación para la población, pero también, la calidad de estas viviendas en relación con el derecho a la ciudad. Así, tal política no contribuyó para el enfrentamiento de los problemas urbanos atados a la cuestión de vivienda, como el transporte y medio ambiente, donde las políticas urbanas no consideran efectivamente las cuestiones envueltas en conjunto.

De ahí la pertinencia del activismo cívico entrar en escena para disputar el juego, como los diversos movimientos sociales urbanos, organizaciones laborales locales, instituciones educacionales, etc., para viabilizar un proyecto utópico de urbanismo. El lugar sería entonces capaz de evidenciar la sociedad, en un espacio para la política identificar y revelar la identidad de los sujetos sociales.

Uno de los principales problemas políticos consiste en saber cómo organizar los movimientos sociales para que estos se constituyan efectivamente como fuerzas revolucionarias, ya que ni siempre las reivindicaciones en las calles son consideradas. Pero los desafíos aún son grandes, dada a la necesidad de una profunda reforma política, solamente posible con la participación y presión de tales movimientos, y no sólo mediante las opiniones de aquellos cuyos intereses personales estén directamente involucrados.

No es posible también realizar una reforma urbana sin que haya una reforma jurídica en el país con vistas a la democracia del suelo urbano y de la vivienda en un escenario de segregación socioespacial. Esa nueva orden jurídico-urbanística fue manifestada en Brasil por medio de la Constitución de 1988 y del Estatuto de la Ciudad, pero los desafíos aún son grandes - heredados de la urbanización del siglo XX sin soporte jurídico aliado a los procesos socioeconómicos - especialmente con relación a la materialización de estas órdenes jurídicas. Por eso, Fernandes (2006) evoca la participación de los juristas en el proceso de producción de las ciudades, que comúnmente queda concentrado a los intereses de los urbanistas.

Se hace importante la renovación de la democracia en las cuestiones urbanas, pues la Constitución de 1988 consolidó la función social de la propiedad como un proceso descentralizado y político democratizado. En ese mote, debe ser garantizada la participación social en las decisiones de las cuestiones urbanas, por medio de, por ejemplo, fórums, consejos, asambleas, etc. y, principalmente, en la discusión y elaboración de los Planes Directores. 
Pero, cabe a la propia sociedad civil, utilizándose de los movimientos sociales urbanos y la participación e interacción en los espacios institucionales, buscar la conquista del derecho a la propiedad como, efectivamente, un derecho público, movilizando el parlamento y las instituciones jurídicas para tal propósito, de forma a reconfigurar la herencia radicada del siglo XX en cuanto a la exclusión socioespacial.

\section{CONCLUSIÓN}

El Programa Mi Casa, Mi Vida (MCMV) representó un gran avance sobre la cuestión de la habitación, pues enserió en la agenda política nacional inversiones en un área que por años fue dejada en segundo plano. Con base en el objetivo propuesto, se concluye que el programa contribuyó con el aumento de habitaciones formales reivindicadas por los movimientos de vivienda, pero, no combatió los problemas con relación al derecho a la ciudad de las capas populares más pobres. Los resultados demostraron que el programa llevó sus beneficiarios a vivir en regiones distantes de los grandes centros urbanos, ampliando horizontalmente las ciudades, sin la realización de un estudio sobre las funciones sociales de propiedades deshabitadas existentes.

Se verifica, aunque el programa no buscó modificar la orden económica vigente desde los años de 1990, la cual llevó la decadencia de las ciudades en la era de la globalización, como los procesos de desindustrialización, crecimiento desordenado, migraciones e insuficiencia de servicios básicos. Estas características reflejan la configuración de la dinámica del mercado capitalista neoliberal, que descalifica el acceso de la amplia mayoría de la sociedad, específicamente a de baja y media renta.

Al considerar que los movimientos de vivienda destinados al combate al estructuralismo del capitalismo vigente, el cual beneficia la pequeña cuota más rica de la sociedad, la configuración del MCMV no va de encuentro a las demandas del movimiento, por dar continuidad al modo excluyente adoptado por las políticas habitacionales del país. A pesar de significar el establecimiento de inversiones en el área de habitación, acaba por beneficiar las grandes contratistas, la especulación inmobiliaria y la transformación de las ciudades en núcleos de reproducción del capitalismo excluyente, además de proporcionar viviendas de baja calidad con costes elevados.

El MCMV colaboró con la profundización de la idea de vivienda como mercancía, como forma de combate a la crisis financiera global de 2008, y reestableció la lógica del BNH. La calidad de vida de los beneficiados por el programa, pertenecientes a las capas de media y baja renta, se torna precaria, pues ellos pasaron a residir lejos de los beneficios advenidos de las ciudades, como los culturales, educacionales y comerciales.

La distancia de las viviendas, causada por la horizontalización de las ciudades perjudica tanto a los habitantes cuanto, a las esferas públicas locales, el habitante es obligado a pasar horas en el tráfico, sea por medio particular o por transporte público, para llegar hasta su trabajo u ocio, el poder público local pasa a ser cobrado cuanto a las inversiones de infraestructura y movilidad, sin el debido suporte de planeamiento y de recursos federales. Frente a tales consecuencias, al mismo tiempo en que el Estado combate una crisis financiera del sector privado, intensifica los problemas de déficits públicos de los entes federativos. 
Mientras tanto, la ciudad es constantemente reconfigurada conforme las demandas del mercado global y sus olas de crisis, con apoyo del propio Estado, como visto, funcionando como un outdoor para atracción de grandes inversiones como forma de sobrevivencia nacional delante de las competiciones fiscales. La especulación inmobiliaria se torna aún más fuerte en un ambiente de segregación de espacios, con maximización de lucros de la élite detentora del segmento inmobiliaria, que cada vez más se valora y excluye el acceso de las capas de baja renta de las ciudades.

La ciudad vuelta al capital se hace una ciudad fantasma durante en la élite, pues el movimiento urbano diario es vuelto para el trabajo y consumo sólo, mientras que sobran casas y edificios residenciales libres debido a sus valores astronómicos. Mientras expulsa la población de los centros urbanos, el gobierno inviste en desarrollo de proyectos espectaculares, tenido por liderazgos como forma de atracción de otros tipos de inversiones y combate a las dificultades financieras advenidas principalmente de gastos públicos sociales.

Por eso, conforme Fernandes (2006) es preciso retirar el derecho a la propiedad del Código Civil, de derechos individuales, y abrazarlo junto a los derechos públicos de los ciudadanos, para que la propiedad cumpla un papel más social. Es necesario aún desarrollar una estrategia de conexiones interurbanas para disminución de la competición para desarrollo menos desigual entre las regiones. Por eso, la política pública habitacional del país no puede más prescindir de la consolidación de la reforma urbana, la cual fue parcialmente instrumentalizada en el Estatuto de la Ciudad de 2001.

Y delante de la cultura hegemónica, formada por la visión de la élite dominante, las ocupaciones de terrenos y edificios vacíos son tratadas como robo o vandalismo tanto por los propietarios cuanto, por parte de las propias clases populares, que pasan una vida toda sin acceso a la vivienda. De esa manera, la necesidad de los movimientos sociales urbanos se organice propagando sus propuestas de forma pública.

Los movimientos de vivienda necesitan continuar ocupando estructuras que no cumplen sus funciones sociales y reivindicando más espacios institucionales de participación en la res publica, pero, principalmente, necesitan movilizar esfuerzos de manifestaciones, tales como aquellas organizadas durante invernada de junio/julio de 2013, para que sus voces resuenen delante de los representantes electos, con vista a que tales manifestaciones demostraron inicialmente la fuerza de las movilizaciones sociales, como una especie de retomada del poder político por la sociedad civil.

En nivel institucional, es necesario aún adoptar una producción social del espacio en la perspectiva del ciudadano, o sea, por la democracia directa. Además de la reforma urbana, El Brasil carece de una reforma política y de mayor compromiso del sistema jurídico cuanto al derecho a la ciudad, pero no ocurrirán cambios significativos mientras la propia sociedad civil, continuar a considerar sus semejantes como villones y a apoyar la continuidad del sistema vigente.

\section{REFERENCIAS}

BASSUL, J. R.. Reforma urbana e estatuto da cidade. Santiago: EURE, v.28, n.84, p.133-144, 2002.
BONDUKI, N. G.. Pioneiros da habitação social: cem anos de construção de política pública no Brasil. 1 ed. São Paulo: UNESP; SESC, 2014. 
BOULOS, G.. Por que ocupamos? Uma introdução à luta dos sem-teto. 2 ed. São Paulo: Scortecci, 2014.

CARDOSO, A. L.; ARAGÃO, T. A.. Do fim do BNH ao programa minha casa minha vida: 25 anos de política habitacional no Brasil. In: CARDOSO, A. L.. PMCMV e seus efeitos territoriais. Rio de Janeiro, Letra Capital, 2013.

DIAS, C. M. M.. Movimentos sociais do século XIX: história e historiografia. In: SIMPÓSIO NACIONAL DE HISTÓRIA, 22. Anais. João Pessoa, 2013.

FERNANDES, E.. A nova ordem jurídico-urbanística no Brasil. In: Direito urbanístico: estudos Brasileiros e Internacionais. Belo Horizonte: Del Rey, 2006.

FERREIRA, R. F. C.. Movimentos de moradia, autogestão e política habitacional no Brasil: do acesso à moradia ao direito à cidade. In: FORUM AMBIENTAL. Anais. 2012.

FIX, M.; ARANTES, P. F.. Como o governo Lula pretende resolver o problema da habitação: Alguns comentários sobre o pacote habitacional Minha Casa Minha Vida. Jornal Correio da Cidadania, 2009.

FIX, M.; PEREIRA, A. L. S.. A Metrópole brasileira nas políticas públicas setoriais. In: FURTADO, B.; KRAUSE, C.; FRANÇA, K..
Território metropolitano, políticas municipais: por soluções conjuntas de problemas urbanos no âmbito metropolitano. 1 ed. Brasília: IPEA, 2013.

HARVEY, D.. Cidades rebeldes: do direito à cidade à revolução urbana. São Paulo: Martins Fontes - selo Martins, 2014.

KLINK, J.. Por que as Regiões Metropolitanas continuam tão ingovernáveis?. In: FURTADO, B.; KRAUSE, C.; FRANÇA, K. Território metropolitano, políticas municipais: por soluções conjuntas de problemas urbanos no âmbito metropolitano. 1 ed. Brasília: IPEA, 2013.

LEFEBVRE, H.; MARTINS, S.; ANDRADE, M. M.. A revolução urbana. Belo Horizonte: UFMG, 2004.

LEFEBVRE, H.. O direito à cidade. São Paulo: Morais, 1991.

OFFE, C.. Partidos políticos y nuevos movimientos sociales. Madrid: Sistema, 1988.

BEM, A. S.. A centralidade dos movimentos sociais na articulação entre o Estado e a sociedade brasileira nos séculos XIX e XX. Educ. Soc., Campinas, v.27, n.97, p.1137$1157,2006$. 